
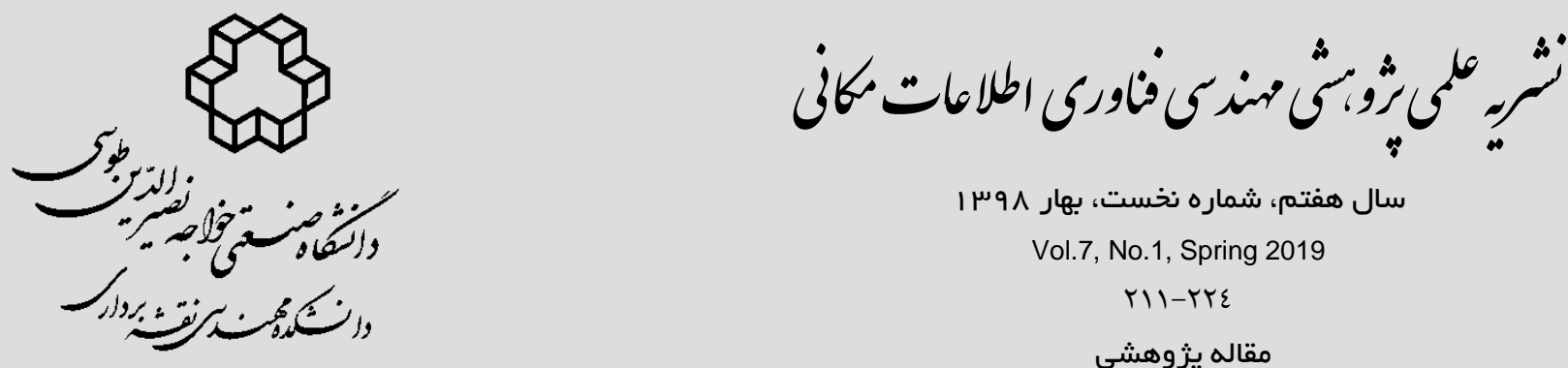

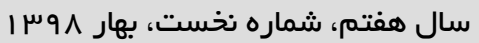

Vol.7, No.1, Spring 2019

KII-TYE

مقاله يزّوهشى

ييشبينى جزر و مد با استفاده از آناليز سرىهاى زمانى مشاهدات بويه

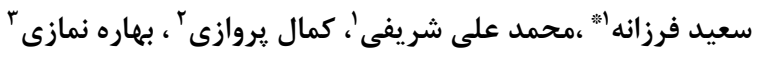

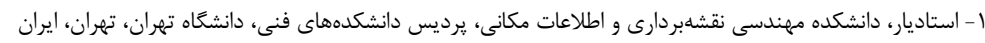

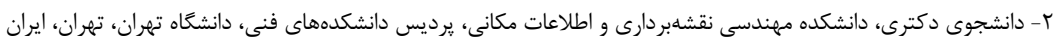

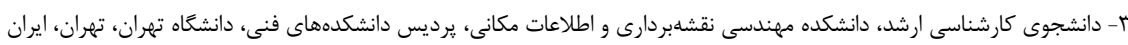

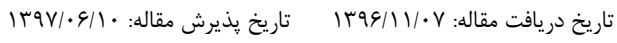

جكيده

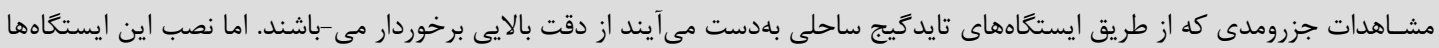

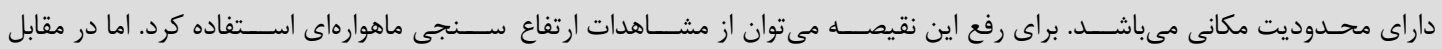

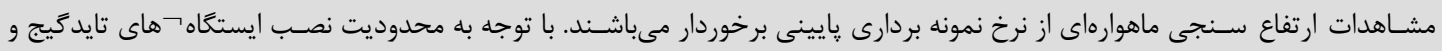

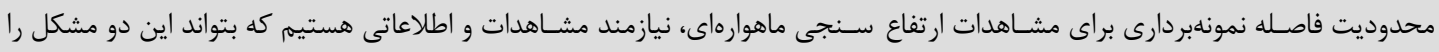

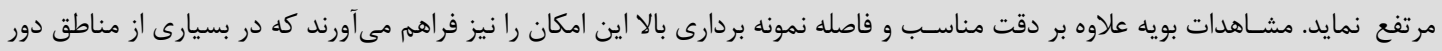

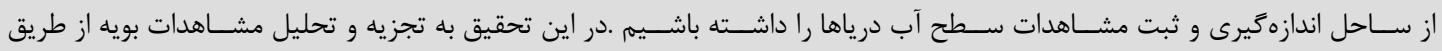

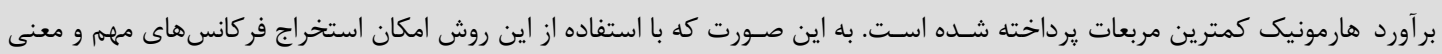

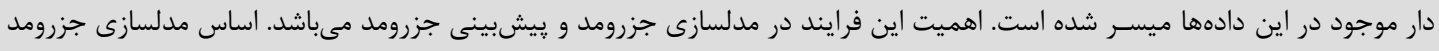

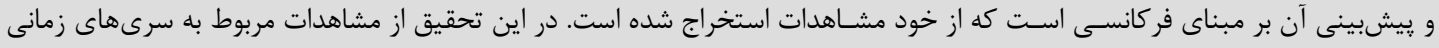

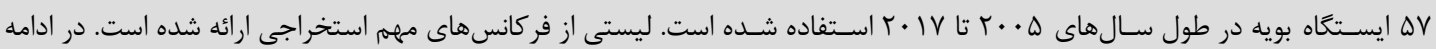

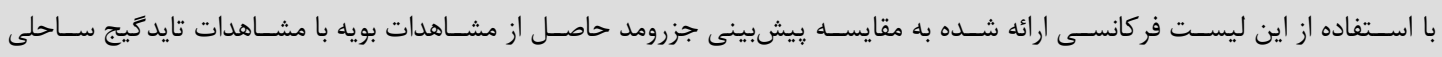

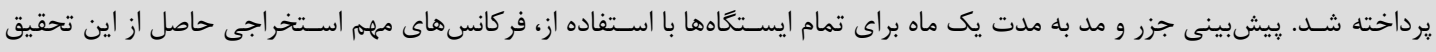

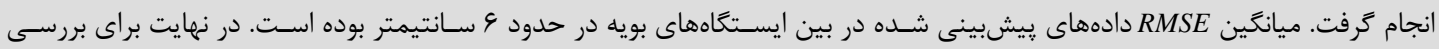

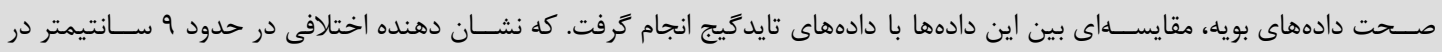
پيش بينى مشاهدات سطح آب بوده است.

كليدوازهها: سرى زمانى ايستگاههاى بويه، برآورد هارمونيك كمترين مربعات(LS-HE) ، فر كانسهاى جزر و مد، ييشبينى جزر و مد 


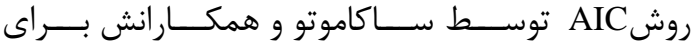
ي يدا كردن مولفههاى غير جزرومدى با باستفاده از برنامه

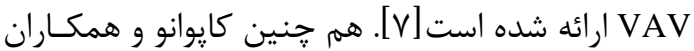

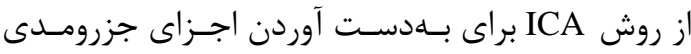
مستقل و غير خطى استفاده كردهاند]ـ] روش برآورد هارمونيك كمترين مربعات (LS-HE) بـاتهـ منظور آناليز طيفى و تشخيص فر كانسهاى موجـود در

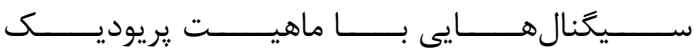

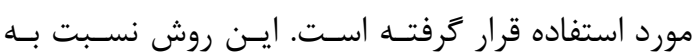

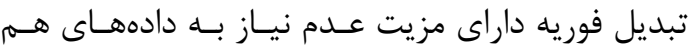

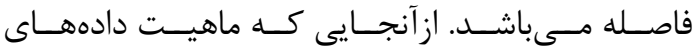

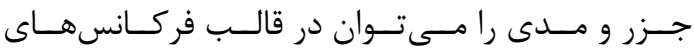

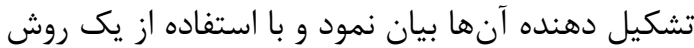
مشاهده مبنا، فر كانسهاى جزرومدى ران را استخر اج كرد.

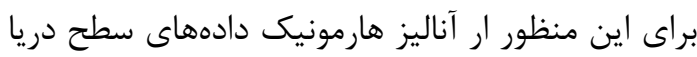
از طريق بسط به سرى فوريه اسـتفاده مسىشـود. آنـاليز

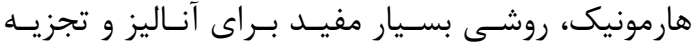

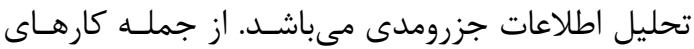

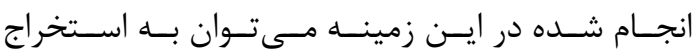
فركانسهاى جزرومدى براى مشاهدات تايد-كـيجهـاى زئس كشور انخسـتان توسـط اميـرى سـيمكويى و همكـاران اشـاره كـرد. موسـويان و مشـهلى حســينعلى از آنـاليز

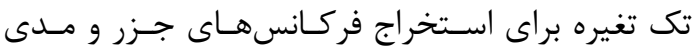

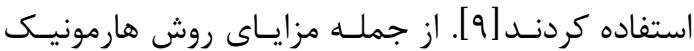

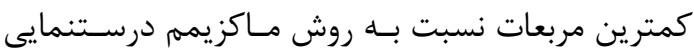

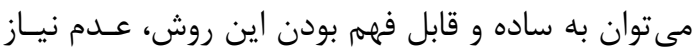

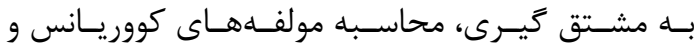
سرعت بالا جهت همكرا شدن اشاره كرد.

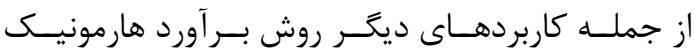

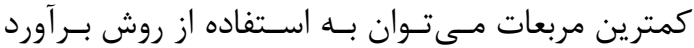
هارمونيك كمترين مربعات جهت آناليز سرىهاى زمانى

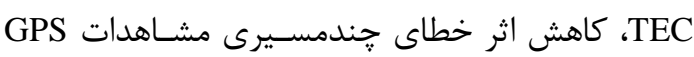

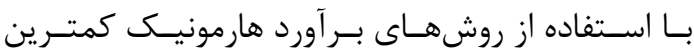

${ }^{3}$ least-squares harmonic estimation
- 1 - - 1قدمه

يديده جزرو مد از ديرباز براى ساكنين منــاطق سـاحلى

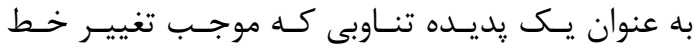

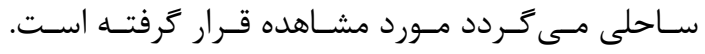
اقيانوس شناسها براى رسيدن به درك بهتر از خـواص

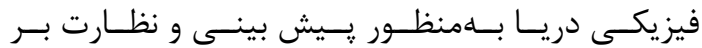

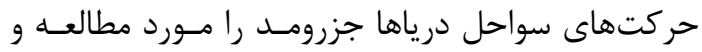
بررسى قرار دادهاند. تلاش در مدلسازى جزرومد سـابقه طولانى داشته و به عنوان يكى از اقدامات اوليه در ايـن

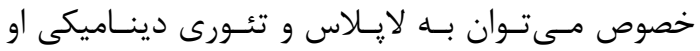

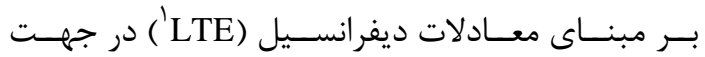
مدلسازى جزرومد در سـطح اقيـانوسهـا اشـاره نمـود.

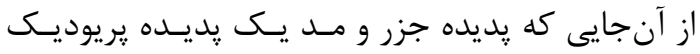

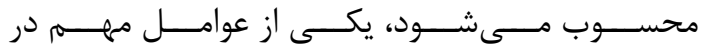

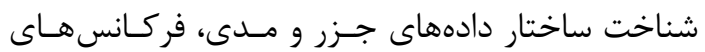

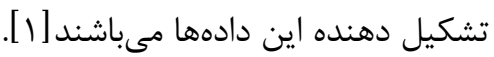

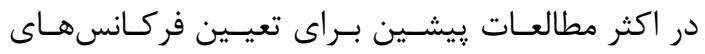

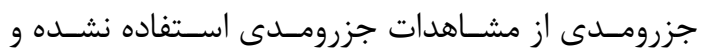
روشهاى مورد استفاده بر مبنــاى اصـول تئسورى بـوده است. در اين روشها يتانسـيل جزرومهـد بـا اسـتفاده از

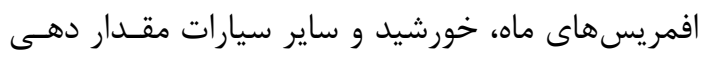

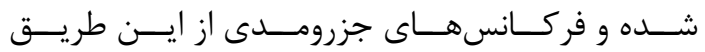

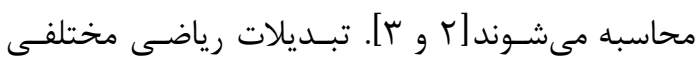

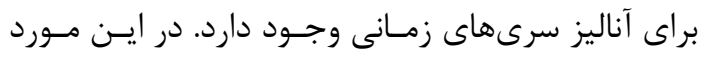

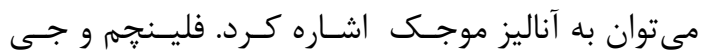

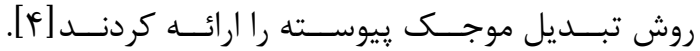

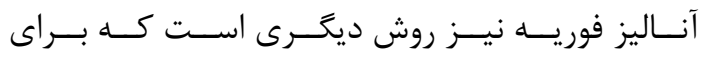

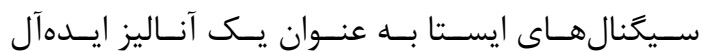
ارائه شده است. هارتمن-ونزل با استفاده از تبديل فوريه

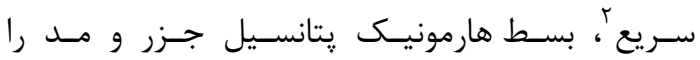

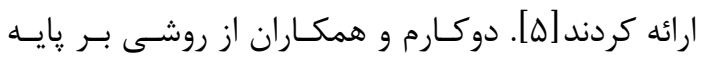

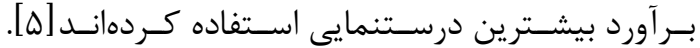

${ }^{1}$ Laplace Tidal Equations

${ }^{2}$ Fast Fourier Transformation 


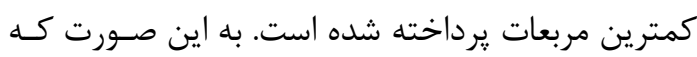

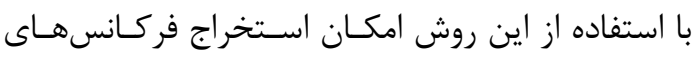

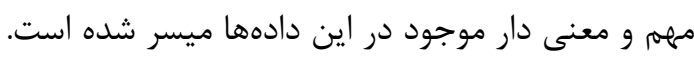

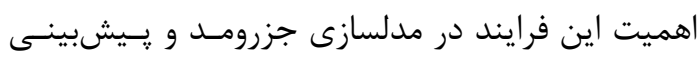

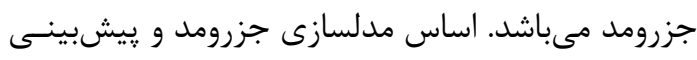

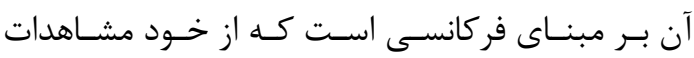
استخراج شده است. در اين تحقيق از مشاهدات مربوط

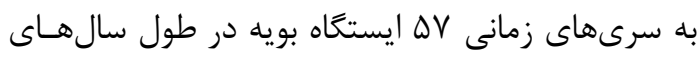

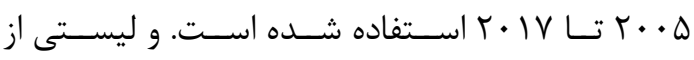

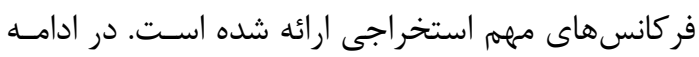

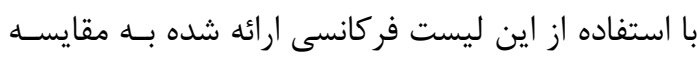

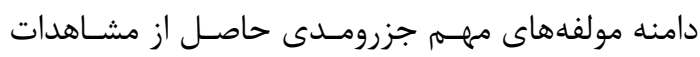

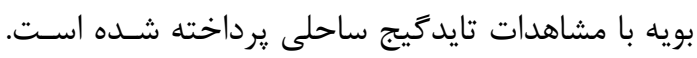

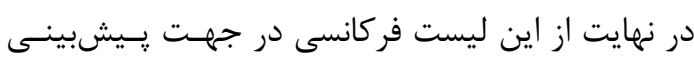

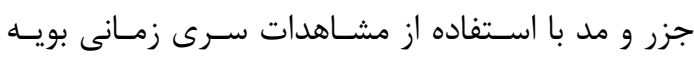

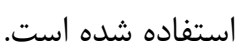

\section{r- كشف مشاهدات اشتباه در سرى هاى زمانى}

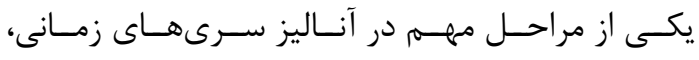

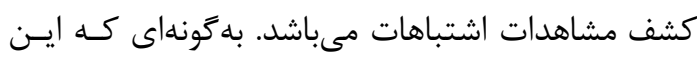

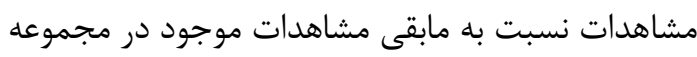

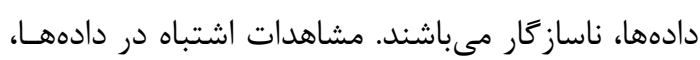

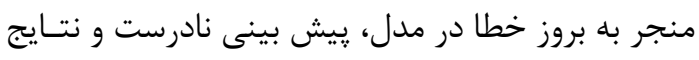

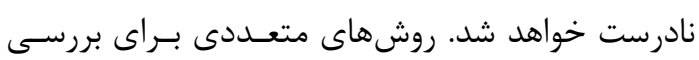

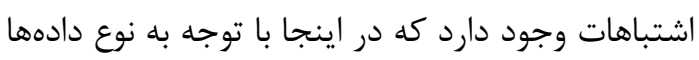

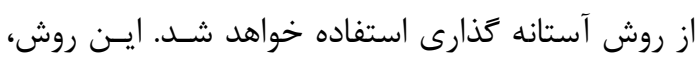

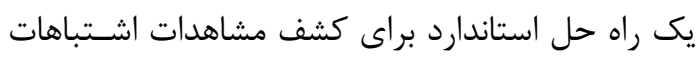

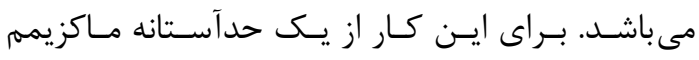

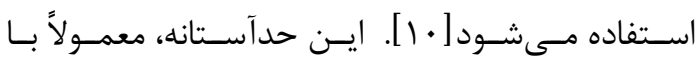

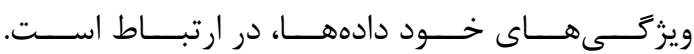

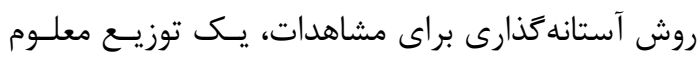

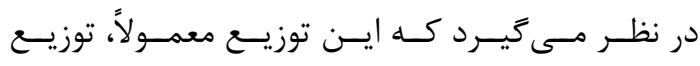
نرمال مىباشد. بنابراين، اگر يك مجموعه داده بهصورت داش $y_{i}=\left\{y_{1}, y_{2}, \ldots, y_{n}\right\}$
مربعات، استفاده از روش هارمونيـك كمتـرين مربعـات

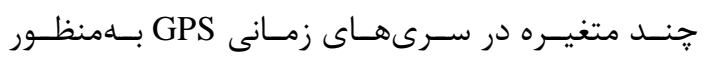

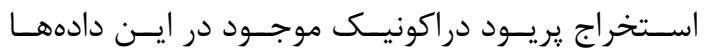

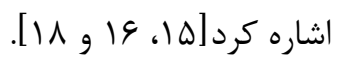

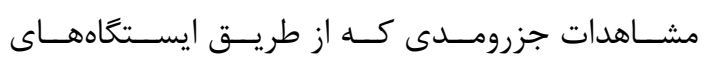

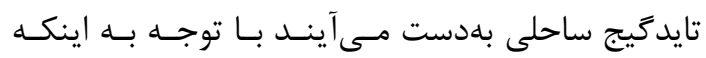

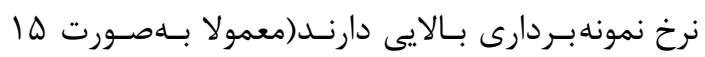

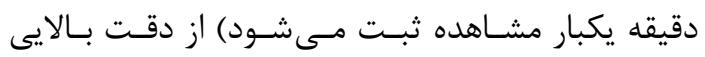

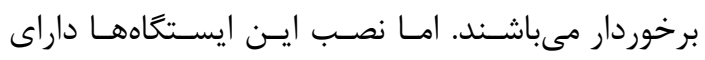
محدوديت مكانى مىباشند به اينصورت كه نمسىتـوان

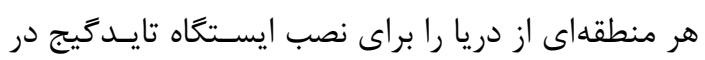

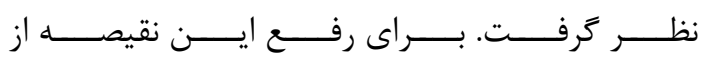

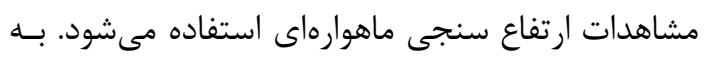

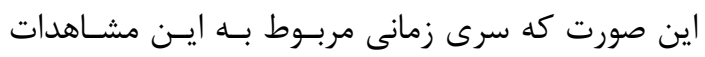

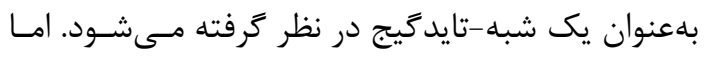

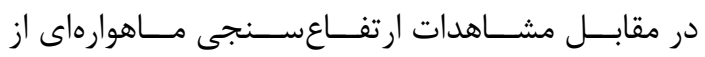

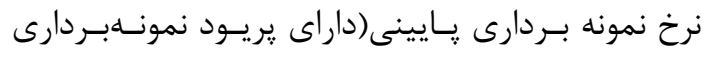

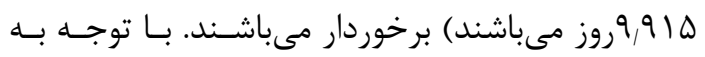

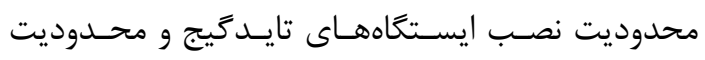

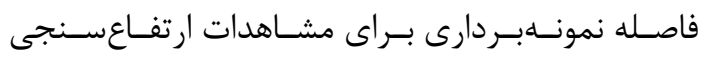

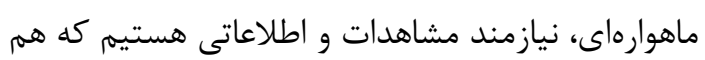

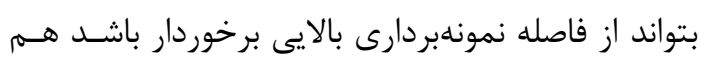

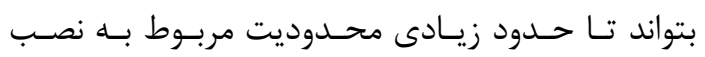
ايستكاههاى تايدگيج را مرتفع نمايد.

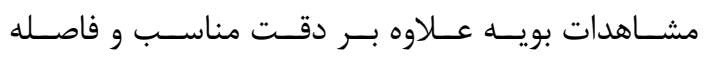

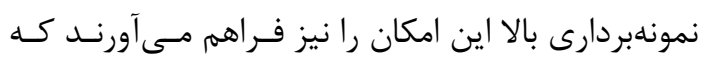

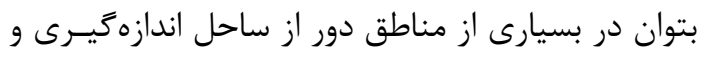

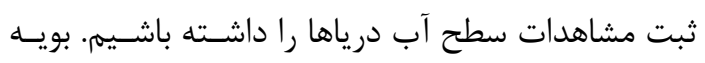
هي از اندازهكيرى و ثبت مشخصات امواج و يارامترهـا،

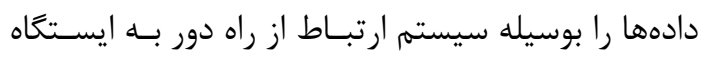

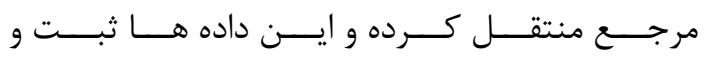
ذخيره مىشوند. با توجه به اهميت اين مشاهدات(فاصله

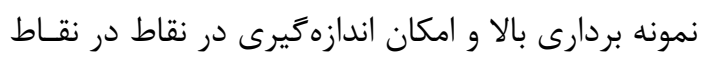

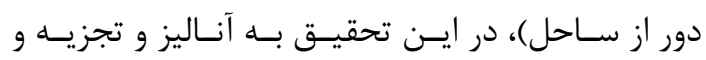

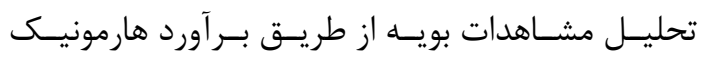


در واقع، اين روش، متناسب بـا مقـــار ه، مشـاهداتى را كــه از توزيــع (N مشاهده اشتباه شناسايى مى كند. لازم به ذكر است كـهـ

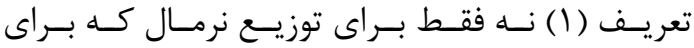

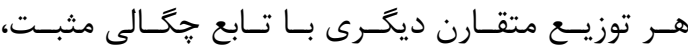

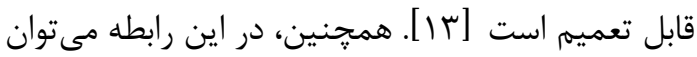

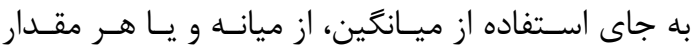

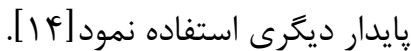

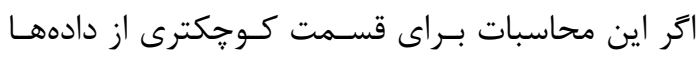

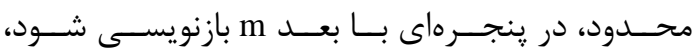
آنغاه محدوده اشتباهات براى آنها عبارتست از: $\operatorname{out}\left(\alpha, \overline{\mathrm{y}}_{\mathrm{m}}, \mathrm{s}_{\mathrm{m}}, \mathrm{m}\right)=\left\{\mathrm{i}=1,2, \ldots, \mathrm{m}:\left|\mathrm{y}_{\mathrm{i}}-\overline{\mathrm{y}}_{\mathrm{m}}\right|>\mathrm{z}_{1-\mathrm{\alpha} / 2} \mathrm{~s}_{\mathrm{m}}\right\}$

ץ-1 - بر آورد هارمونيــ كمتــرين مربعـات تـــ

براى يك سرى زمانى، ساده ترين رفتار يريـوديكى كـهـ مى توان به منظور بهبود مدل تابعى، به آن اضافه نمـود،

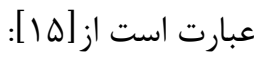

$$
y(t)=a_{k} \cos \omega_{k} t+b_{k} \sin \omega_{k} t
$$

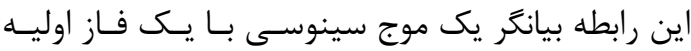

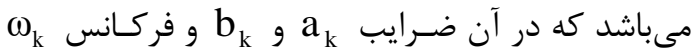

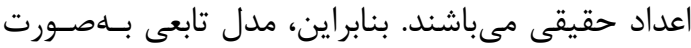

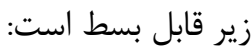

$\mathrm{E}(\underline{\mathrm{y}})=\mathrm{Ax}+\mathrm{A}_{\mathrm{k}} \mathrm{x}_{\mathrm{k}}$

(أبطه هم حنين داريم: رابطه (a) $A_{k}=\left[\begin{array}{cc}\cos \omega_{k} t_{1} & \sin \omega_{k} t_{1} \\ \cos \omega_{k} t_{2} & \sin \omega_{k} t_{2} \\ \vdots & \vdots \\ \cos \omega_{k} t_{m} & \sin \omega_{k} t_{m}\end{array}\right], \quad x_{k}=\left[\begin{array}{l}a_{k} \\ b_{k}\end{array}\right]$

$\omega_{k}$ شه مامل دو ستون مربوط به فركـانس A كاتريس

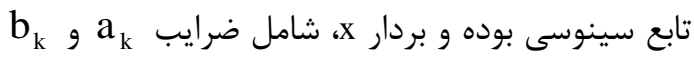

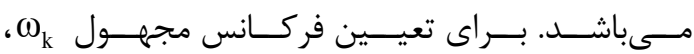
با استفاده از روش برآورد هارمونيك كمتـرين مربعـات،

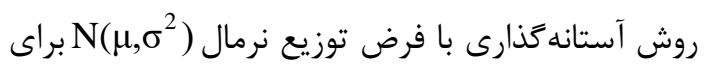

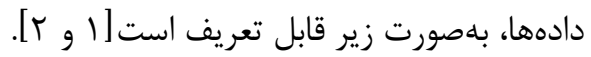

رابطه (1)

$\operatorname{out}(\alpha, \mu, \sigma)=\left\{\mathrm{i}=1,2, \ldots, \mathrm{n}:\left|\mathrm{y}_{\mathrm{i}}-\mu\right|>\mathrm{z}_{1-\alpha / 2} \sigma\right\}$

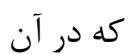

out $(\alpha, \mu, \sigma)$ ميانكَين و انحراف معيار (مجهول) دادهها،

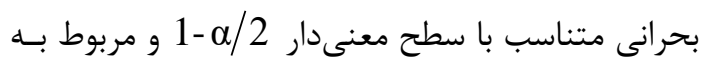
توزيع نرمال استاندارد، مىباشند.

) رابطه (T) كه در آن out $\left(\alpha, \bar{y}_{m}, s_{m}, m\right)$ و $\bar{y}_{m} ، y \in R^{n}$ مشاهدات بـردار $y_{i}=\left\{y_{1}, y_{2}, \ldots, y_{m}\right\}$ به به ترتيب برآوردهايى از ميـانخين و انحــراف معيـار m داده مذكور مىباشند. اخـــر

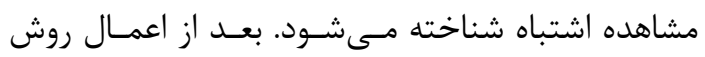

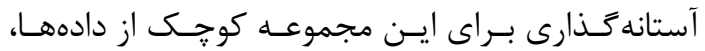

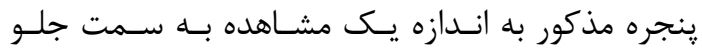

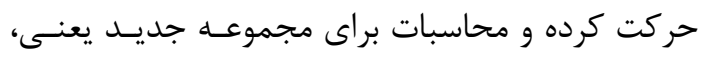

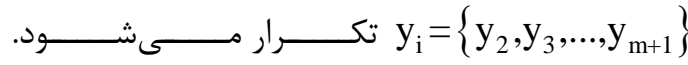

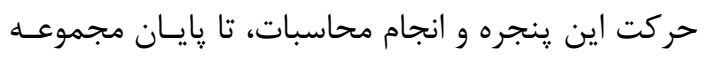
دادهها ادامه مىيابد. حسـن ايسن روش، بـار محاسـباتى إنى

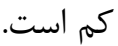
r- مبانى بر آورد هارمونيك كمترين مربعات

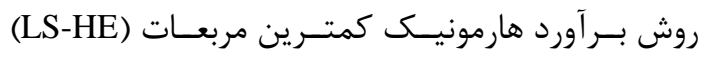

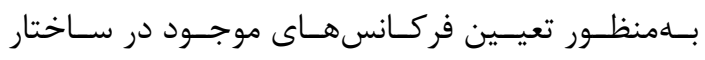

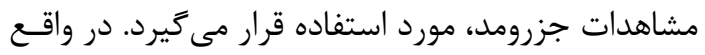
اين روش، يك سرى الخوهاى يريوديك را در قالب توابع

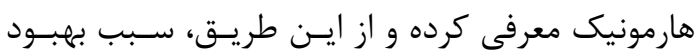
مدل تابعى مى كردد. 


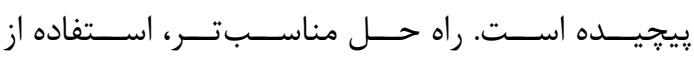

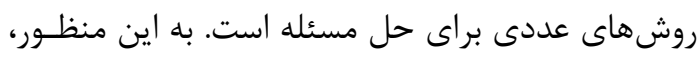
مسى برقرار كرد و نمودار مقادير طيفى م مقادير كستسته

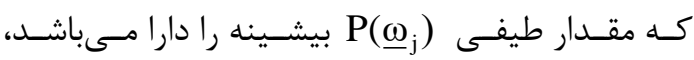
بلهنوان فر كانس مدنظر انتخاب نمود. انتخــاب صورت مى گيرد: (9)

$\mathrm{T}_{\mathrm{j}+1}=\mathrm{T}_{\mathrm{j}}\left(1+\alpha \mathrm{T}_{\mathrm{j}} / \mathrm{T}\right), \quad \alpha=0.1, \quad \mathrm{j}=1,2, \ldots$

$\underline{\omega}_{j}=2 \pi / T_{j}$

كه در آن، T1، يريود نايكويست بـوده و T، طـول كـل

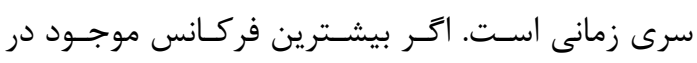

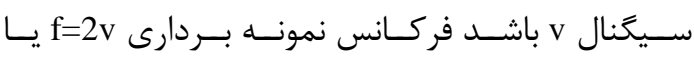

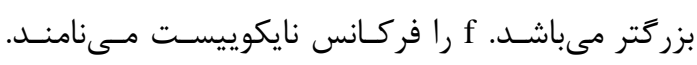

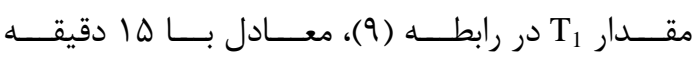

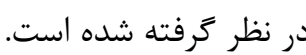

r-r- بر آورد هارمونيك كمتــرين مربعـات جنــــ

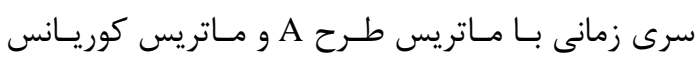

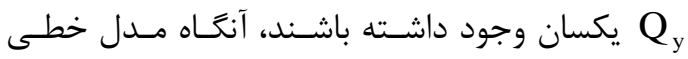
مذكور به حالت جندمتغيره تعميم مىيابـد. بـراى يــ

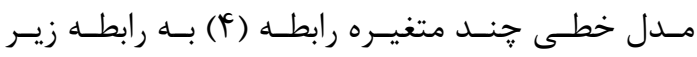
تعميم مىيابد [ع|]

\section{متغيره}

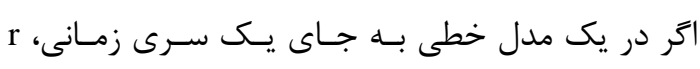

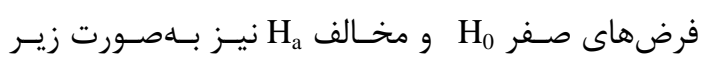
تعريف مىشوند :

رابطه (ع)

$\mathrm{H}_{0}: \mathrm{E}(\underline{\mathrm{y}})=\mathrm{Ax}$

$\mathrm{H}_{\mathrm{a}}: \mathrm{E}(\underline{\mathrm{y}})=\mathrm{Ax}+\mathrm{A}_{\mathrm{k}} \mathrm{x}_{\mathrm{k}}$

در واقع علت در نظر گرفتن اين دو فرض اين است كـه،

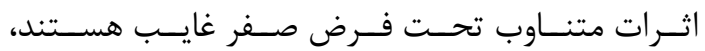
در حالى كه تحت فرض مقابل حضور دارنـــ هـدف مـا

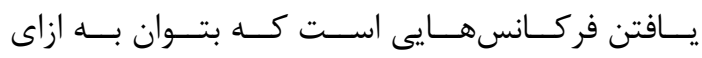
اين فر كانسها ماكزيمم طيف توانى را بهدست آورد. $\underline{\omega}_{\mathrm{k}}=\underset{\omega_{\mathrm{j}}}{\operatorname{argmax}} \mathrm{P}\left(\underline{\omega}_{\mathrm{j}}\right)$

رابطه (V)

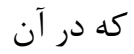
رابطه ( ) (1)

$P\left(\underline{\omega}_{j}\right)=\underline{\hat{e}}_{0}^{\mathrm{T}} \mathrm{Q}_{\mathrm{y}}^{-1} \mathrm{~A}_{\mathrm{j}}\left(\mathrm{A}_{\mathrm{j}}^{\mathrm{T}} \mathrm{Q}_{\mathrm{y}}^{-1} \mathrm{P}_{\mathrm{A}}^{\perp} \mathrm{A}_{\mathrm{j}}\right)^{-1} \mathrm{~A}_{\mathrm{j}}^{\mathrm{T}} \mathrm{Q}_{\mathrm{y}}^{-1} \underline{\mathrm{e}}_{0}$

در رابطه (ᄉ) مربعات و در رابطه

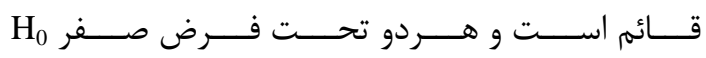
بهدست مى آيند [ه ا1 ].

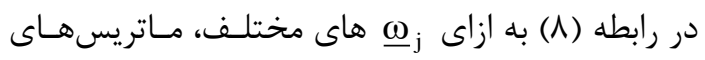

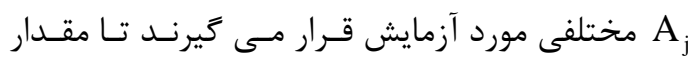

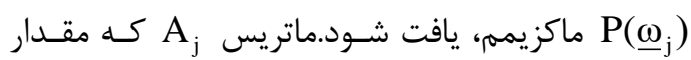

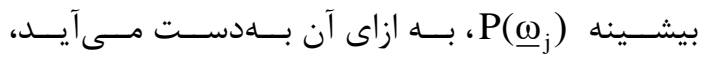
بلهنوان ماتريس A A انتخاب مى شود.

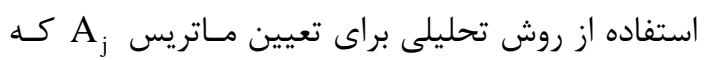

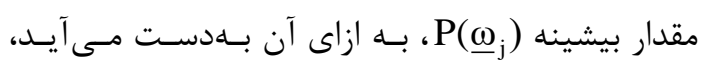

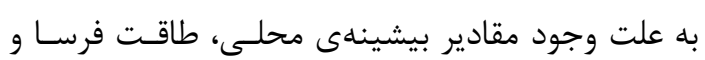
$\mathrm{E}(\operatorname{vec}(\underline{\mathrm{Y}}))=\left(\mathrm{I}_{\mathrm{r}} \otimes \mathrm{A}\right) \operatorname{vec}(\mathrm{X})+\left(\mathrm{I}_{\mathrm{r}} \otimes \mathrm{A}_{\mathrm{k}}\right) \operatorname{vec}\left(\mathrm{X}_{\mathrm{k}}\right), \mathrm{D}(\operatorname{vec}(\underline{\mathrm{Y}}))=\Sigma \otimes \mathrm{Q}$

رابطه (•)

اجزاى ماتريس $\Sigma$ با بعد r×r و مجهولات متعلق بــه كه در آن

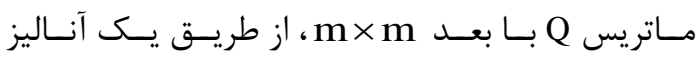

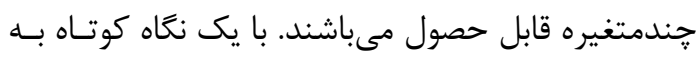

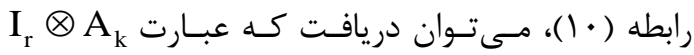

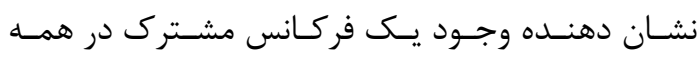

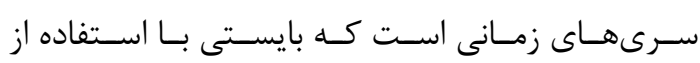

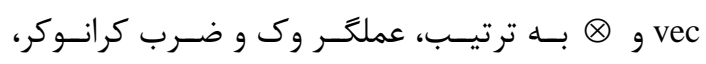

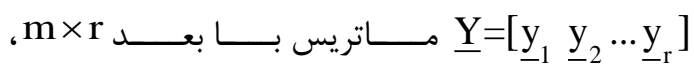

$$
\begin{aligned}
& \mathrm{X}_{\mathrm{k}}\left[={ }_{1} \mathrm{x}_{\mathrm{k}} \quad \mathrm{k} \quad, \quad \mathrm{X}=\left[\begin{array}{lll}
\mathrm{x}_{1} & \mathrm{x}_{2} \ldots \mathrm{x}_{\mathrm{r}}
\end{array}\right]\right. \\
& \text { ماتريس هاى شامل بردار مجهولات، بـه ترتيـب بـا بعـد }
\end{aligned}
$$

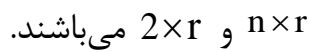


سهم فر كانسهاى مختلف در بازسازى سرىهاى زمانى

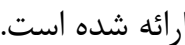

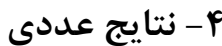

در اين تحقيق ار دادههـاى له ايسـتخاه بويـهـ اسـتفاده

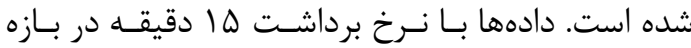

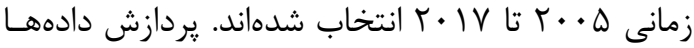
با اسـتفاده از نـرمافززار GAMIT انجـام كرفتـهـ اسـت.

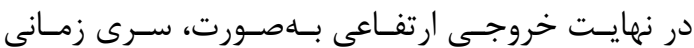

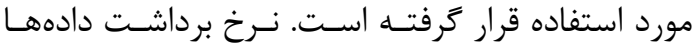
بلهـورت ا ثانيـهاى بـوده اسـت. بــا توجـهـ بــهـ اينكـهـ

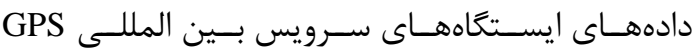

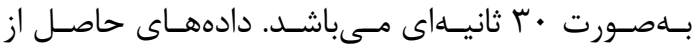

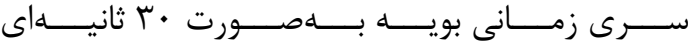

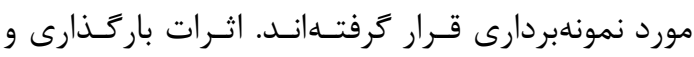

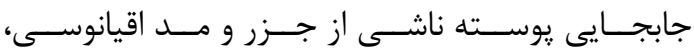

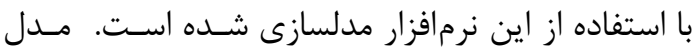

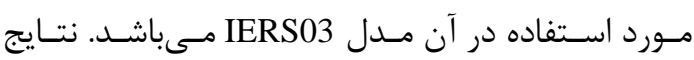

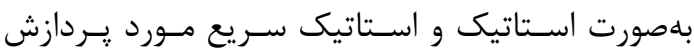

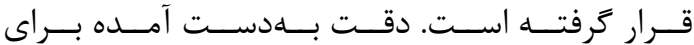

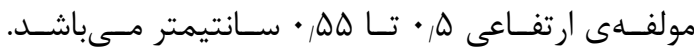

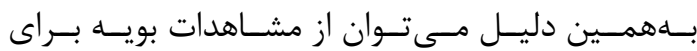
آنـاليز سـطح متوسـط آب درياهـا اسـتفاده كـرد [ IV] موقعيـت و مختصــات ايـن ايسـتعاههــا در شـكل (1) ارائه شده است. - است

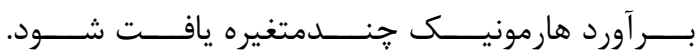
رابطه طيف توانى در حالت جندمتغيره، بـهـــورت زيـر قابل بازنويسى است [هـا ] رابطه (1)

$P\left(\underline{\omega}_{j}\right)=\operatorname{tr}\left(\underline{\hat{E}}^{\mathrm{T}} \mathrm{Q}^{-1} \mathrm{~A}_{\mathrm{j}}\left(\mathrm{A}_{\mathrm{j}}^{\mathrm{T}} \mathrm{Q}^{-1} \mathrm{P}_{\mathrm{A}}^{\perp} \mathrm{A}_{\mathrm{j}}\right)^{-1} \mathrm{~A}_{\mathrm{j}}^{\mathrm{T}} \mathrm{Q}^{-1} \underline{\hat{E}} \Sigma^{-1}\right)$

r به عنوان باقيماندههاى كمترين مربعـات

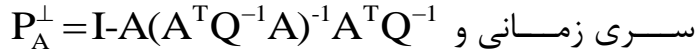

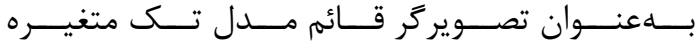

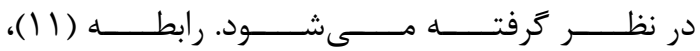
همه سرىهاى زمانى را بلطور همزمان در نظر گرفته و

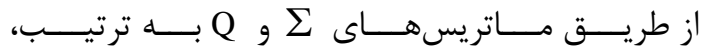
كراس كروليشن و وابستگى زمانى را به حساب مى مئ آورد.

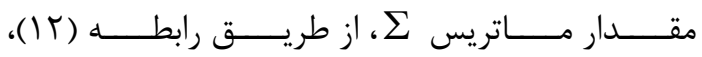
قابل برآورد است: - است $\underline{\hat{\Sigma}}=\frac{\underline{\hat{E}}^{\mathrm{T}} \mathrm{Q}^{-1} \hat{\underline{E}}}{\mathrm{~m}-\mathrm{n}}$

رابطه (T)

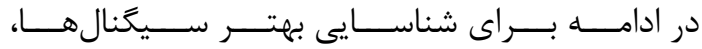

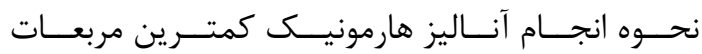
به دو صورت تك متغيره، بـراى تـك تـك مولفـهـهـاى

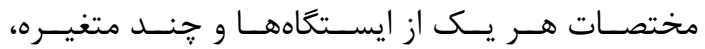

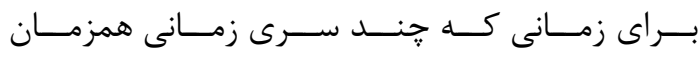

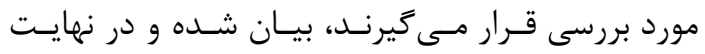

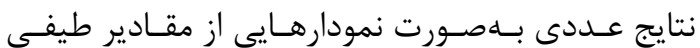
براى مجموعهاى از $\mathrm{P}\left(\underline{\omega}_{\mathrm{j}}\right)$ 
ييشبينى جزر و مد با استفاده از آناليز سرى هاى زمانى...

سعيد فرزانه و همكاران

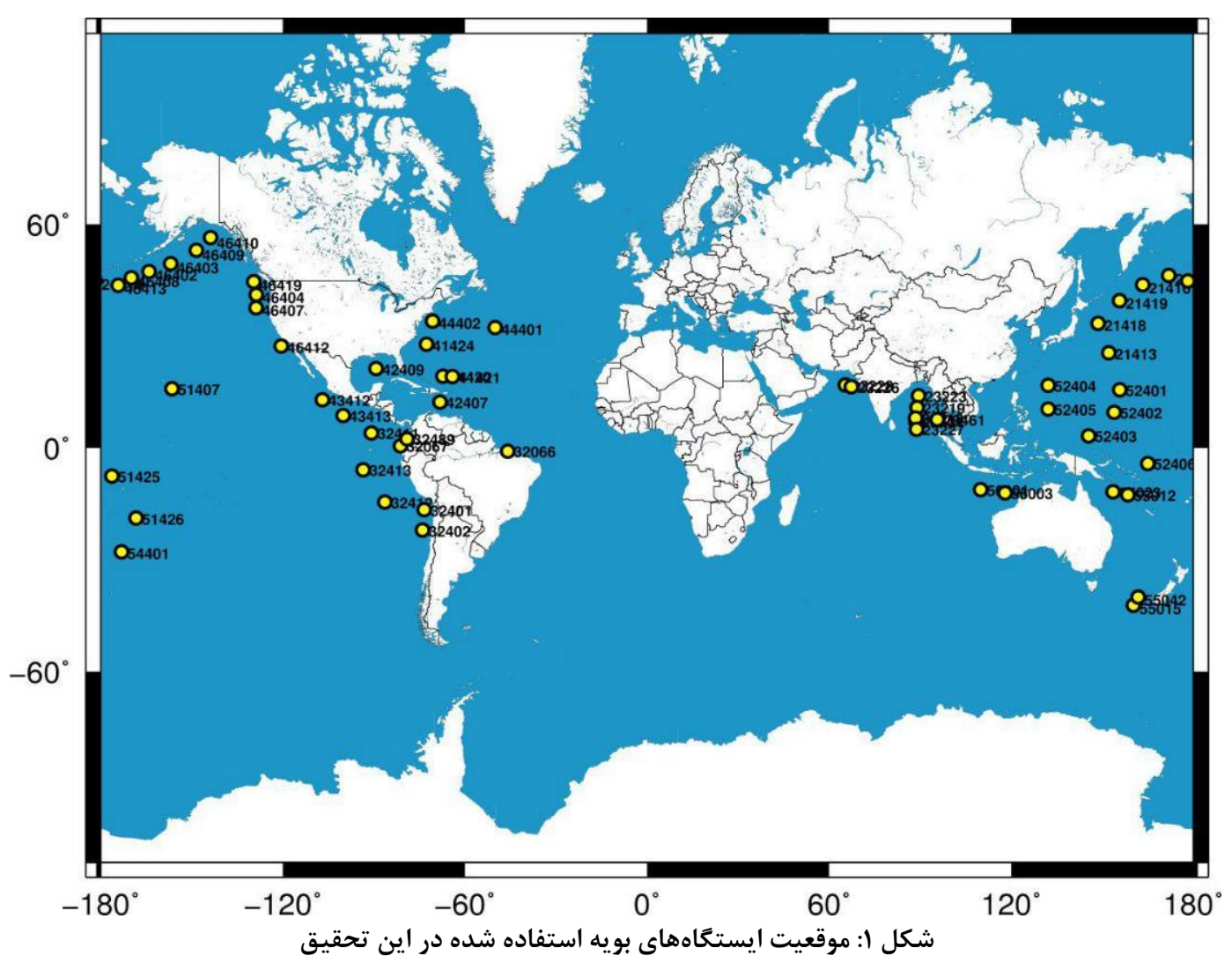

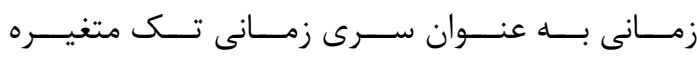
محاسبه كرديده است. به اين ترتيب طيف تـوانى در دو دو زئس حالت مورد بررسى قرار گرفت، حالت اول با اسـتفاده از

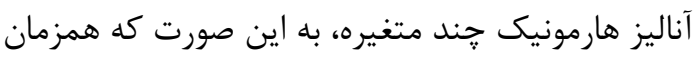

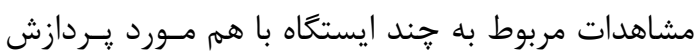

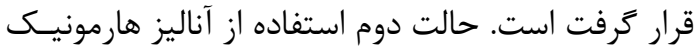
تك متغيره، به اين صورت كـه مشـاهدات سـرىزمـانى

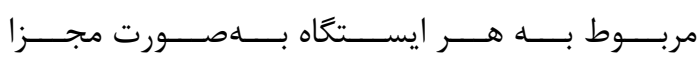

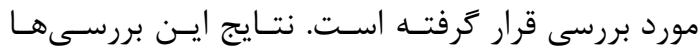

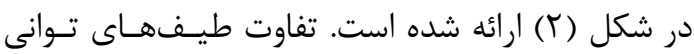

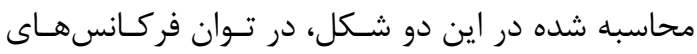

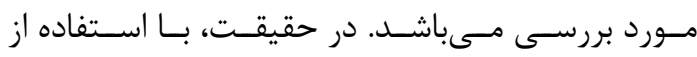

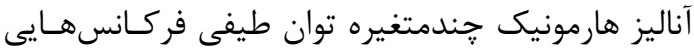
كه بين سرى هاى زمانى مشترك بوده اسـت، بيشـتر از

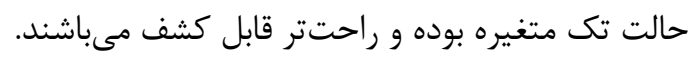

F -1- آناليز طيفى دادههاى جزرو مدى در ابتـدا، آنـاليز جنــدمتغيره و تـكـ متغيــره، از طريـق

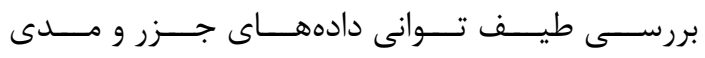

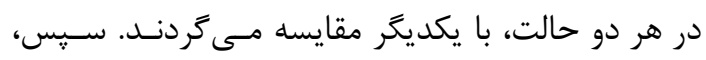

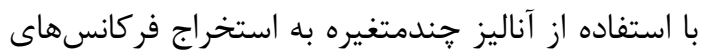
جزر و مدى يرداخته مىشود. دادههـاى مــورد اسـتفاده

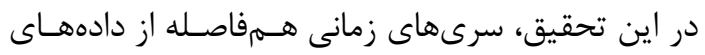
جزر و مدى DV ايستخاه بويه مىباشند.

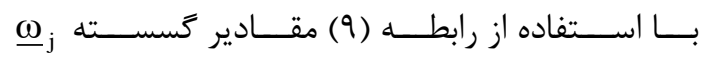
محاسبه مىشود. در اين رابطه با توجه به اينكه نياز بـهـ محاسبه طيف توانى مىباشد، مقـدار دقيقه در نظر گرفته شده است. سيس بله محاسبه طيف

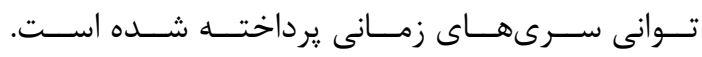

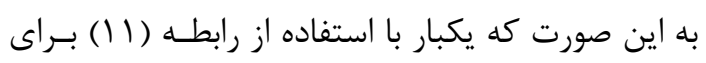

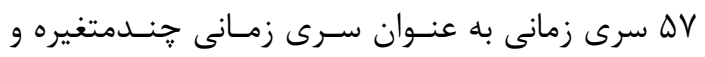

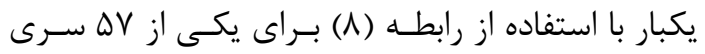




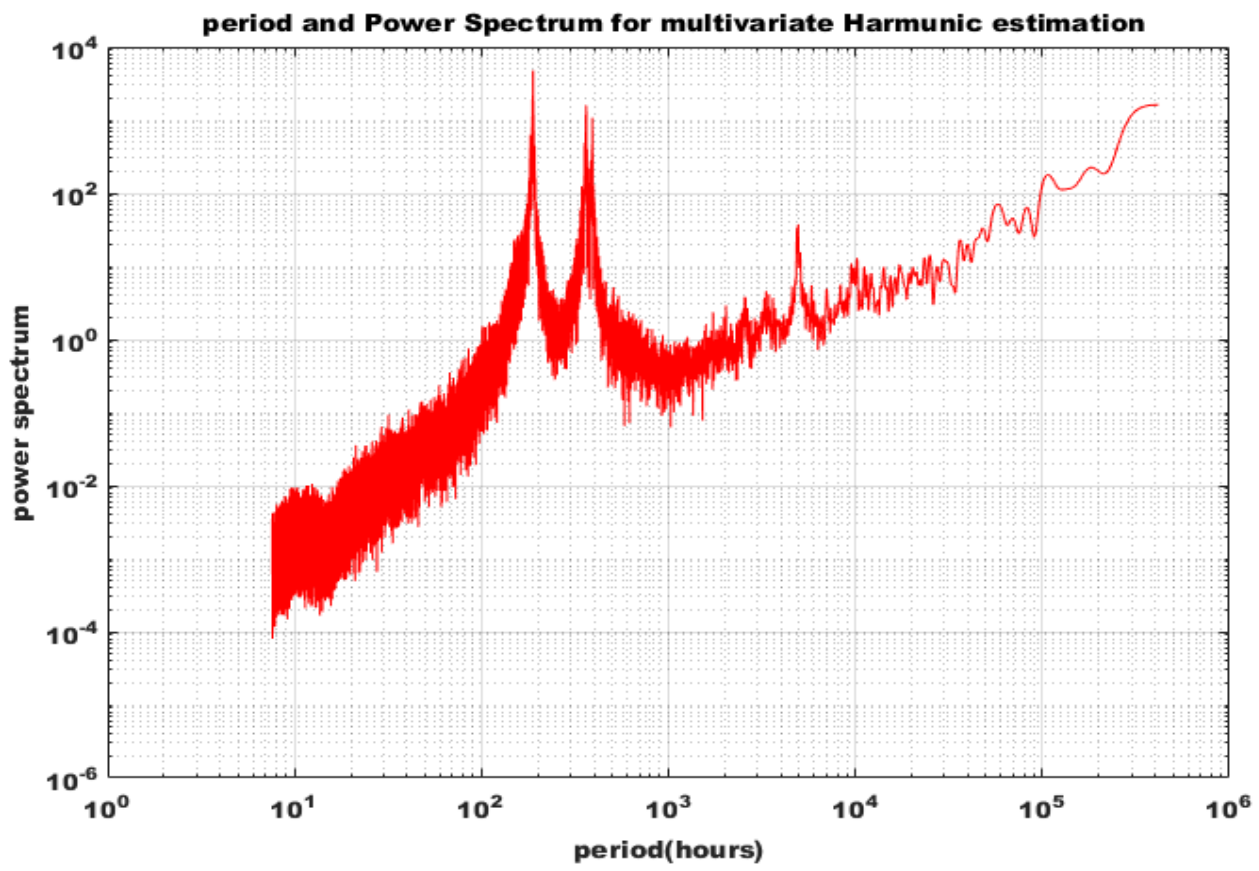

(a)

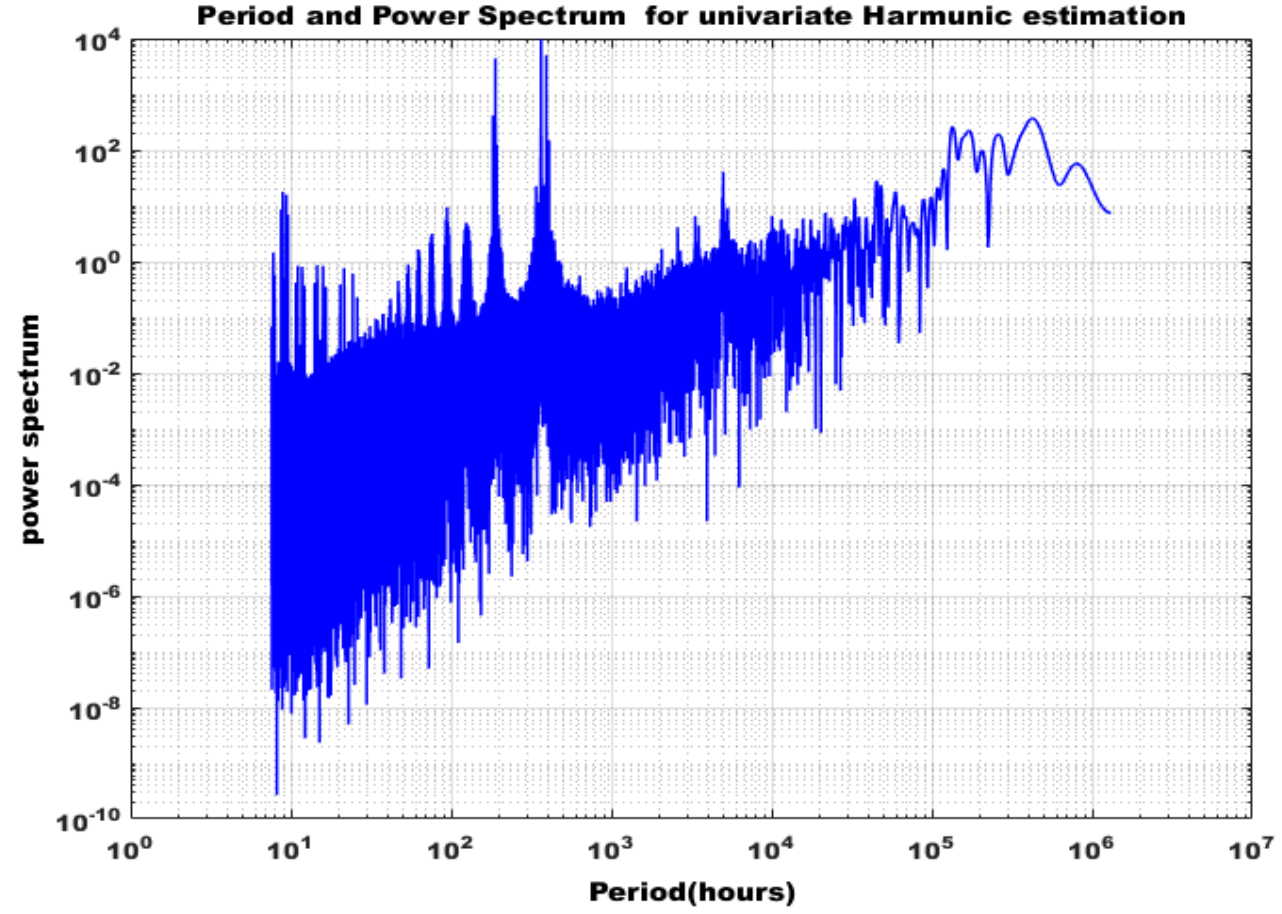

(b)

شكل r: طيف توانى קندمتغيره كمترين مربعات اخذ شده از DV ايستغاه بويه با نرخ برداشت ها دقيقه (شكل a). طيف توانى

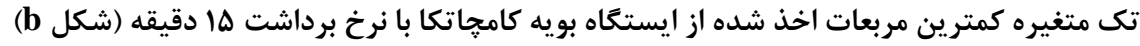




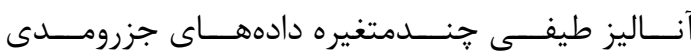

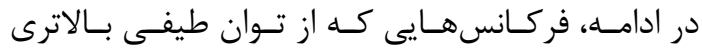

$$
\begin{aligned}
& \text { ايستخاههاى بويه ارائه شد. } \\
& \text { برخوردار بودهاند، استخراج گرديدهانـد. در جــدول (Y)، } \\
& \text { ليستى از فركانس هاى مهمم استخراج شده با اسـتفاده از بودهاز }
\end{aligned}
$$

\begin{tabular}{|c|c|c|c|c|c|}
\hline فركانس(دور در & شماره & فر كانس(دور در & شماره & فر كانس(دور در & شماره \\
\hline 0.0419644295 & 99 & 0.0812196884 & 50 & 0.2458664158 & 1 \\
\hline 0.0418773167 & 100 & 0.0806534343 & 51 & 0.2441231120 & 2 \\
\hline 0.0417935544 & 101 & 0.0805395142 & 52 & 0.2429805211 & 3 \\
\hline 0.0416997408 & 102 & 0.0804993054 & 53 & 0.2415328929 & 4 \\
\hline 0.0416461310 & 103 & 0.0804121901 & 54 & 0.2397236328 & 5 \\
\hline 0.0415690708 & 104 & 0.0802513601 & 55 & 0.2055028704 & 6 \\
\hline 0.0414618575 & 105 & 0.0800938818 & 56 & 0.2041134285 & 7 \\
\hline 0.0413378899 & 106 & 0.0799464546 & 57 & 0.2024738318 & 8 \\
\hline 0.0410061922 & 107 & 0.0798392347 & 58 & 0.2008319875 & 9 \\
\hline 0.0406610895 & 108 & 0.0797018584 & 59 & 0.1996793501 & 10 \\
\hline 0.0406610895 & 109 & 0.0795644846 & 60 & 0.1984060849 & 11 \\
\hline 0.0388216782 & 110 & 0.0794539134 & 61 & 0.1633946688 & 12 \\
\hline 0.0388216782 & 111 & 0.0792830328 & 62 & 0.1619203662 & 13 \\
\hline 0.0387312162 & 112 & 0.0791456575 & 63 & 0.1610230242 & 14 \\
\hline 0.0386508061 & 113 & 0.0790518398 & 64 & 0.1595115078 & 15 \\
\hline 0.0373675790 & 114 & 0.0789546715 & 65 & 0.1247345375 & 16 \\
\hline 0.0371095937 & 115 & 0.0788910105 & 66 & 0.1233138520 & 17 \\
\hline 0.0365768707 & 116 & 0.0787871404 & 67 & 0.1223689645 & 18 \\
\hline 0.0363356397 & 117 & 0.0786263110 & 68 & 0.1220630717 & 19 \\
\hline 0.0361279111 & 118 & 0.0786263110 & 69 & 0.1206735294 & 20 \\
\hline 0.0356957036 & 119 & 0.0785056888 & 70 & 0.1192193426 & 21 \\
\hline 0.0348848992 & 120 & 0.0782577442 & 71 & 0.1026307230 & 22 \\
\hline 0.0348848992 & 121 & 0.0782543931 & 72 & 0.1001440648 & 23 \\
\hline 0.0343052731 & 122 & 0.0778690736 & 73 & 0.0983682238 & 24 \\
\hline 0.0332130357 & 123 & 0.0777819573 & 74 & 0.0956776570 & 25 \\
\hline 0.0195269712 & 124 & 0.0777819573 & 75 & 0.0934930407 & 26 \\
\hline 0.0192422059 & 125 & 0.0777149453 & 76 & 0.0848517641 & 27 \\
\hline 0.0186090254 & 126 & 0.0776311789 & 77 & 0.0847177381 & 28 \\
\hline 0.0186090254 & 127 & 0.0775842706 & 78 & 0.0842855084 & 29 \\
\hline 0.0074909103 & 128 & 0.0774066887 & 79 & 0.0838700311 & 30 \\
\hline 0.0059503333 & 129 & 0.0772525603 & 80 & 0.0836153831 & 31 \\
\hline 0.0030809389 & 130 & 0.0770981009 & 81 & 0.0835316173 & 32 \\
\hline 0.0030809389 & 131 & 0.0766259963 & 82 & 0.0834143453 & 33 \\
\hline 0.0026090389 & 132 & 0.0764048555 & 83 & 0.0833741383 & 34 \\
\hline 0.0014917575 & 133 & 0.0762581509 & 84 & 0.0833104763 & 35 \\
\hline 0.0009871746 & 134 & 0.0760898977 & 85 & 0.0832434637 & 36 \\
\hline 0.0008836716 & 135 & 0.0759692759 & 86 & 0.0831965549 & 37 \\
\hline 0.0007501889 & 136 & 0.0759290692 & 87 & 0.0831261928 & 38 \\
\hline 0.0006101478 & 137 & 0.0758419534 & 88 & 0.0829955183 & 39 \\
\hline 0.0006068153 & 138 & 0.0758419534 & 89 & 0.0829318569 & 40 \\
\hline 0.0004170744 & 139 & 0.0755269960 & 90 & 0.0826403527 & 41 \\
\hline 0.0003174619 & 140 & 0.0755269960 & 91 & 0.0826403527 & 42 \\
\hline
\end{tabular}




\begin{tabular}{|c|c|c|c|c|c|}
\hline فر كانس(دور در & شماره & فركانس(دور در & شماره & فر كانس(دور در & شماره \\
\hline 0.0002644584 & 141 & 0.0754298277 & 92 & 0.0824292624 & 43 \\
\hline 0.0002281591 & 142 & 0.0750780146 & 93 & 0.0820942002 & 44 \\
\hline 0.0001852246 & 143 & 0.0741599480 & 94 & 0.0820472929 & 45 \\
\hline 0.0001458093 & 144 & 0.0445275602 & 95 & 0.0819869808 & 46 \\
\hline 0.0001425338 & 145 & 0.0442729219 & 96 & 0.0818663586 & 47 \\
\hline \multirow[t]{2}{*}{0.0001140741} & 146 & 0.0442729219 & 97 & 0.0818228010 & 48 \\
\hline & & 0.0421319538 & 98 & 0.0816452172 & 49 \\
\hline
\end{tabular}

بازه زمانى يك ماهه بهطـور مجـزا در جــداول (ب و أ)،

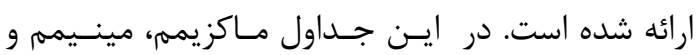

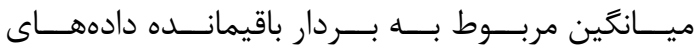
ييشبينى شده با هم مقايسه و نتايج ارائه شده است.
در ادامه براى بررسى دقت مشاهدات ايستخاههاى بويسه

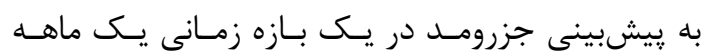

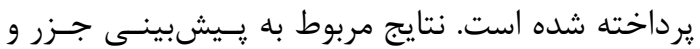

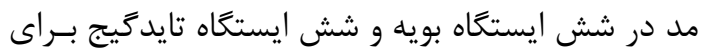

جدول r: بردار باقيماندهها در هر يك از ايستخاههاى بويه و تايدگيج براى يك ماه بيشبينى جزرومد

\begin{tabular}{|c|c|c|c|c|c|c|}
\hline Station & Tide1 & Tide2 & Tide3 & Tide4 & Tide5 & Tide6 \\
\hline RMSE(m) & 0.162 & 0.144 & 0.118 & 0.152 & 0.093 & 0.201 \\
\hline Station & Buoy1 & Buoy2 & Buoy3 & Buoy4 & Buoy5 & Buoy6 \\
\hline RMSE(m) & 0.091 & 0.103 & 0.066 & 0.041 & 0.042 & 0.030 \\
\hline
\end{tabular}

جدول F: ماكزيمم، مينيمم و ميانگين بردار باقيماندهها در هر يك از ايستخاههاى بويه و تايدگيج براى يك ماه بيشبينى جزرومد

\begin{tabular}{|c|c|c|}
\hline Station & Tide & Buoy \\
\hline Maximum(m) & 0.201 & 0.103 \\
\hline Minimum(m) & 0.093 & 0.030 \\
\hline Average(m) & 0.145 & 0.062 \\
\hline
\end{tabular}

به دادههاى معلوم و نمودار سبز و آبى رنغ مربـوط بـــ دادههاى ييشبينى شده مىباشد.

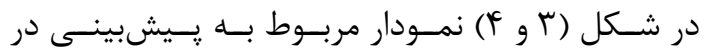

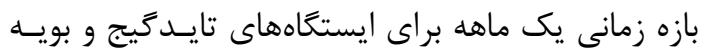
ارائه شده است. در اين اشكال نمودار قرمز رنت مربوط 

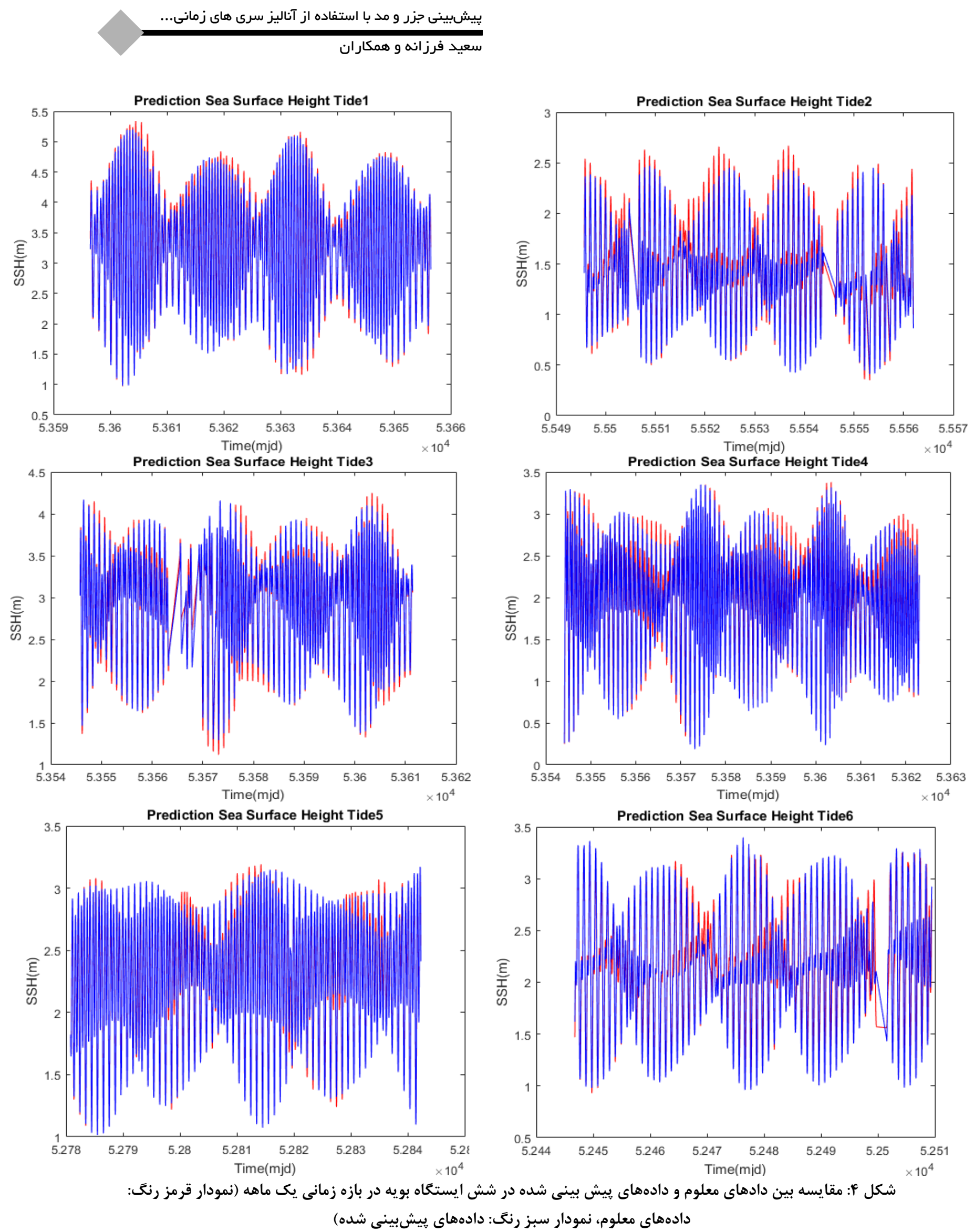

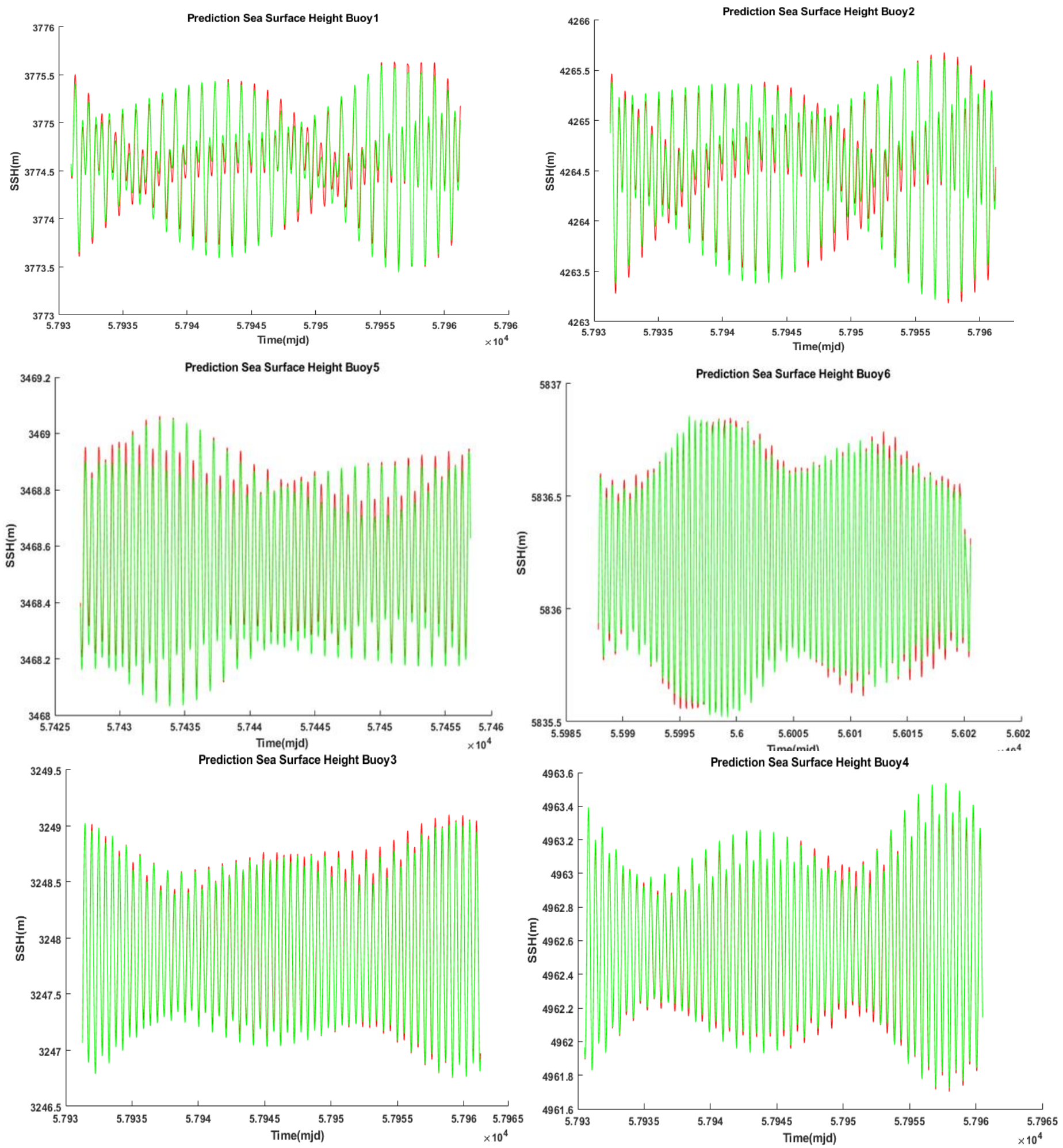

شكل F (ادامه): مقايسه بين دادههاى معلوم و دادههاى ييش بينى شده در شش ايستگًاه بويه در بازه زمانى يك ماهه

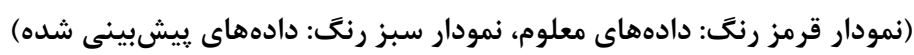




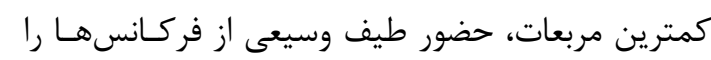

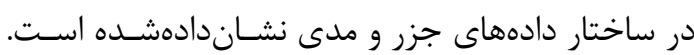

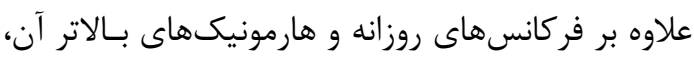

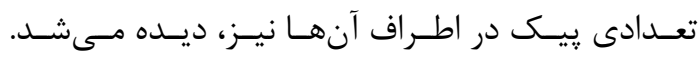

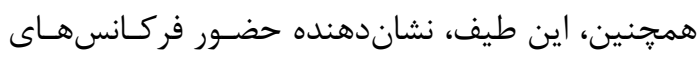

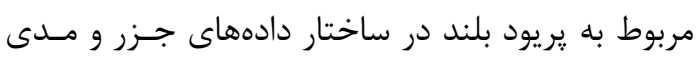

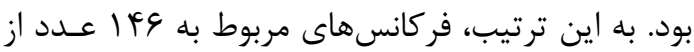
يُيكهايى كه در طيف קندمتغيره داراى تـوان بـالاترى

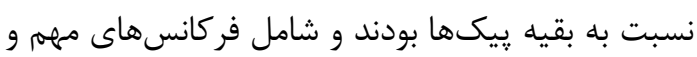

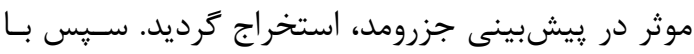

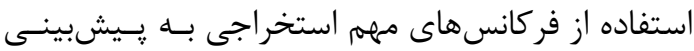

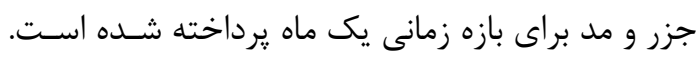
بر اساس نتايج ارائه شده، ييشبينى جزر و و مد بر بر اساس

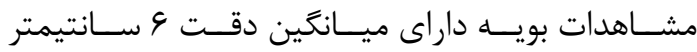

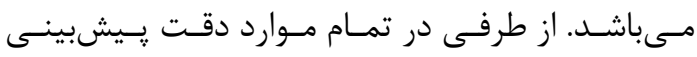
مشاهدات بويه نسبت به مشاهدات ايستخاههاى تايدكيج از دقت بالاترى در حدود 9 سانتيمتر برخـوردار بودنــد. كه اين نشان دهنده دقت بالاى مشاهدات بويه مى باشاشد.

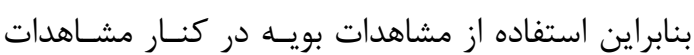

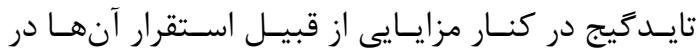

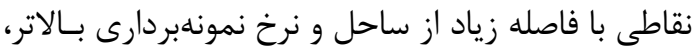

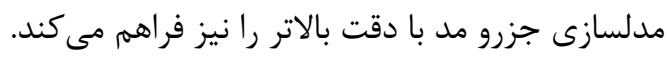

[1] K. C. Cheng, "Analysis of water level measurements using GPS", PhD Thesis, The Ohio State University, 2005.

[2] F. J. Büllesfeld, "Ein Beitrag zur harmonischen Darstellung des gezeitenerzeugenden Potentials", Deutsche Geodaetische Kommission Bayer, Akad, Wiss. 314, 1985.

[3] D. E. Cartwright, and R. J. Tayler, "New computations of the tide-generating potential", Geophysical Journal International, 1971.

[4] E. P. Flinchem, and D. A. Jay, "An introduction to wavelet transform tidal

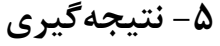

هـدف اصـلى در ايـن تحقيـق اسـتخراج فركـانسهــاى

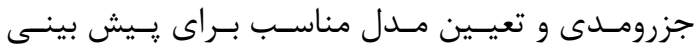

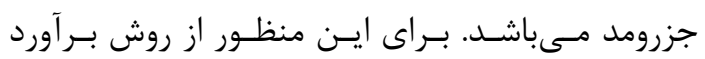

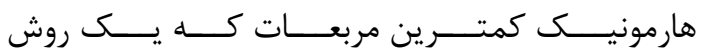

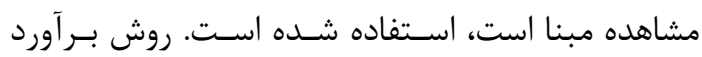

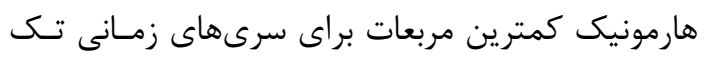

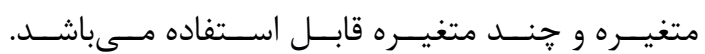
در اين تحقيق در ابتدا مقايسهى بين آناليز קنــدمتغيره

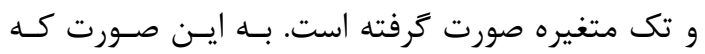

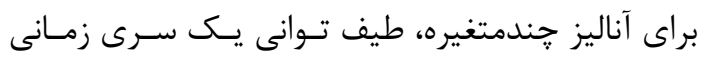

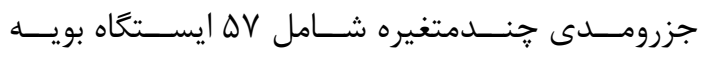
محاسـبه كرديـده اسـت و بــراى حالـت تـك متغيـره،

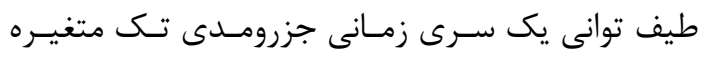

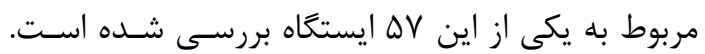

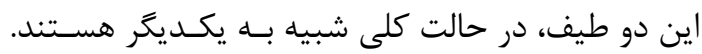

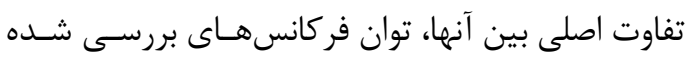

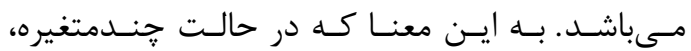
فر كانسهاى مشترك بررسى

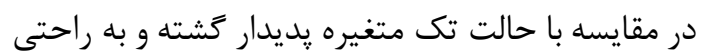
قابل كشف هستند. با بررسى طيف توانى سـرى زمـانى

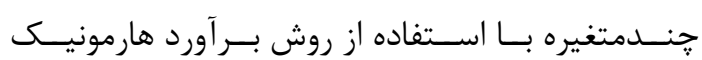

\section{مراجع}

analysis methods", Estuarine, Coastal and Shelf Science 51, 2000.

[5] T. Hartmann, and H. G. Wenzel, "The harmonic development of the Earth tide generating potential due to the direct effect of the planets", Geophysical research letters 21, 1994.

[6] B. Ducarme, A. P. Venedikov, A. R. Mesquita, C. A. Sampaio, D. S. Costa, D. Blitzkow, R. Vieira, and S. R. C. Freitas, "New analysis of a 50 years tide gauge record at Cananéia (SP-Brazil) with the VAV tidal analysis program", In Dynamic Planet, pp. 453-460. Springer, Berlin, 
Heidelberg, 2007.

[7] Y. Sakamoto, M. Ishiguro, and G. Kitagawa, G, " Akaike information criterion statistics", Dordrecht, The Netherlands: D. Reidel, 81, 1986.

[8] P. Capuano, E. De Lauro, S. De Martino, and M. Falanga, "Water-level oscillations in the Adriatic Sea as coherent self-oscillations inferred by independent component analysis", Progress in oceanography 91, 2011.

[9] R. Mousavian, and M. Mashhadi Hossainali, "Detection of main tidal frequencies using least squares harmonic estimation method", Journal of Geodetic Science 2, 2012.

[10] V. Barnett, and T. Lewis, "Outliers in statistical dataWiley", 1974.

[11] A. R. Amiri-Simkooei, S. Zaminpardaz, and M. A. Sharifi, "Extracting tidal frequencies using multivariate harmonic analysis of sea level height time series", J Geod, 2014.

[12]L. Davies, and U. Gather, "The identification of multiple outliers", Journal of the American Statistical Association, 1993.

[13]I. Ben-Gal, O. Maimon, and L. Rockach, "Data Mining and Knowledge Discovery Handbook A Complete Guide for Practitioners and Researchers", Kluwer Academic Publishers, 2005.
[14] M. Kern, T. Preimesberger, M. Allesch, R. Pail, J. Bouman, and R. Koop, "Outlier detection algorithms and their performance in GOCE gravity field processing ", J Geod, 2005.

[15]A. R. Amiri-Simkooei, and J. Asgari,“ Harmonic analysis of total electron contents time series: methodology and results", GPS Solut, 2012.

[16] A. R. Amiri-Simkooei,“ Least-squares variance component estimation: theory and GPS applications", PhD thesis, Mathematical Geodesy and Positioning, Faculty of Aerospace Engineering, Delft University of Technology , Delft, Netherlands, 2007.

[17]C.Chen, W. Zhai, L.Yan, Q. Zhang, X. Zhang, J. Zhu, and S.He, "Assessment of the GPS buoy accuracy for altimeter sea surface height calibration", IEEE Geoscience and Remote Sensing Symposium, 3101-3104. (2014).

[18] A. R. Amiri-Simkooei, T. H. Mohammadloo, and D.F. Argus, "Multivariate analysis of GPS position time series of JPL second reprocessing campaign", Journal of Geodesy, 91(6), pp.685-704. 2017. 


\title{
Tidal prediction using time series analysis of Buoy observations
}

\author{
Saeed Farzaneh ${ }^{*}$., Mohammad Ali Sharifi ${ }^{1}$, Kamal Parvazi ${ }^{2}$, Bahare Namazi ${ }^{3}$ \\ 1- Assistant Professor, School of Surveying and Geomatics Engineering, Faculty of Engineering, University of Tehran, Iran \\ 2- $\quad$ PhD Student of Geodesy, School of Surveying and Geomatics Engineering, Faculty of Engineering, University of Tehran, Iran \\ 3- Msc. Student of Geodesy, School of Surveying and Geomatics Engineering, Faculty of Engineering, University of Tehran, Iran
}

\begin{abstract}
Although tidal observations which are extracted from coastal tide gages, have higher accuracy due to their higher sampling rate, installing these types of gages can impose some spatial limitation since we cannot use every part of sea to install them. To solve this limitation, we can employ satellite altimetry observations. However, satellite altimetry observations have lower sampling rate. According to spatial limitation in installing tide gages and lower rate of satellite altimetry observations, we need observation as along with gathered information which can solve those two main margins. Buoy observations not only for its higher accuracy and sampling rate, but also because of its exclusive features can let us observe further coastal regions to record sea level observations. In this study, buoy observations are analyzed using Least Square Harmonic Estimation (LSHE) method. According to this, important frequencies in those data can be extracted. This process is equally important in Tidal modeling as well as prediction. Tidal modeling and prediction are based on frequency which is derived from observations. In this contribution, time-series data of 57 buoy stations from 2005 to 2017 are processed and a list of important frequencies is prepared. In the following, the comparison between tidal prediction modeling extracted from buoy and tide gage observation was made by using this frequency list. Tide prediction of all the stations during a month was made according to important frequency list extracted in this study. The average RMSE for predicted data in buoy stations has been about $6 \mathrm{~cm}$. Finally, to validate buoy's data, comparison between buoy and tide gage data was made which $\backslash$ represents about $9 \mathrm{~cm}$ difference in sea level prediction.
\end{abstract}

Key words: Buoy observations, Time series analysis, Least square harmonic estimation, Tidal frequency, Tidal Prediction.

Correspondence Address. School of Surveying and Geospatial Engineering, College of Engineering, University of Tehran, North Kargar Ave., Jalal Al. Ahmad Crossing, Tehran, Iran.

Tel: $+98(0) 2188008841$.

Email: farzaneh@ut.ac.ir 